\title{
Endoscopic eradication therapies for Barrett's esophagus
}

\author{
Praveen Sridhar, Virginia R. Litle \\ Division of Thoracic Surgery, Department of Surgery, Boston University School of Medicine, Boston Medical Center, Boston, MA, USA \\ Contributions: (I) Conception and design: All authors; (II) Administrative support: VR Litle; (III) Provision of study materials or patients: All authors; \\ (IV) Collection and assembly of data: All authors; (V) Data analysis and interpretation: All authors; (VI) Manuscript writing: All authors; (VII) Final \\ approval of manuscript: All authors. \\ Correspondence to: Dr. Virginia R. Litle, MD. Division of Thoracic Surgery, Department of Surgery, Boston University, 88 East Newton Street, \\ Collamore Building, Suite 7380, Boston, MA 02118, USA. Email: Virginia.litle@bmc.org.
}

\begin{abstract}
Gastroesophageal reflux disease along with its end stage manifestations such as intestinal metaplasia, dysplasia, and neoplasia have become increasingly prevalent in the United States and Western countries. Intestinal metaplasia, or Barrett's Esophagus (BE), is a well described pre-malignant entity that can progress to esophageal adenocarcinoma. While esophageal adenocarcinoma is challenging to treat, early stage disease can still be cured with esophagectomy and perioperative chemoradiation therapy. Despite multimodality therapy, recurrence rates remain high even for early stage disease. Surveillance endoscopy of patients with BE may identify dysplastic changes or carcinoma in-situ prior to the development of invasive cancer. Endoscopic eradication therapies are a low-risk approach to treat dysplastic lesions and non-dysplastic lesions in high-risk patients to subvert progression to adenocarcinoma. Endoscopic mucosal resection (EMR), radiofrequency ablation (RFA), and cryotherapy are current endoscopic therapies that are safe and effective in the management of $\mathrm{BE}$.
\end{abstract}

Keywords: Barrett's Esophagus (BE); endoscopic eradication; endoscopic mucosal resection (EMR); radiofrequency ablation (RFA) of Barrett's

Received: 15 October 2019. Accepted: 30 December 2019; Published: 10 January 2021.

doi: $10.21037 /$ shc. 2020.02 .08

View this article at: http://dx.doi.org/10.21037/shc.2020.02.08

\section{Introduction}

The stratified, non-keratinized squamous mucosa of the esophagus is a protective barrier that prevents the passage of potentially damaging luminal contents (1). Chronic gastroesophageal reflux can alter this protective barrier by producing a spectrum of changes in the esophageal epithelium $(1,2)$. These changes range from reflux esophagitis to intestinal metaplasia defined by the presence of goblet cells, also known as Barrett's esophagus (BE). $\mathrm{BE}$ is a premalignant lesion that can further progress from a non-dysplastic entity to low-grade dysplasia (LGD), high-grade dysplasia (HGD), or adenocarcinoma of the esophagus (EAC) (3).

The incidence of EAC has drastically increased in the United States and similar Western countries (4,5). Over half of patients with newly diagnosed EAC present with advanced disease. Patients diagnosed with stage I and II disease can undergo curative therapy, however still experience a $20-50 \%$ disease recurrence rate $(4,5)$. While the annual risk of progression from $\mathrm{BE}$ to EAC is less than $1 \%$, the risk of progression from dysplastic BE to EAC can be as high as $6 \%$ annually (1). Therefore, it is imperative identify and eradicate dysplastic BE that may progress to $\mathrm{EAC}(6,7)$. New endoscopic technologies that can be performed during surveillance of patients with $\mathrm{BE}$ provide an opportunity to intervene on the progression of $\mathrm{BE}$ to EAC (8-10).

Endoscopic mucosal resection (EMR), radiofrequency ablation (RFA), and cryotherapy are emerging endoscopic therapies that are performed on patients with $\mathrm{BE}$ and dysplasia or EAC in-situ (8-10). We will review the existing literature and describe techniques for performing these endoscopic therapies in patients with BE. 


\section{Indications for endoscopic therapy}

Patients with chronic reflux symptoms should undergo endoscopy with white-light endoscopy with standardized reporting of mucosal changes, the location of the gastroesophageal junction, the location of the squamocolumnar junction (Z-line), and the location of the diaphragmatic indentation should be completed (11). The diagnosis of BE with or without dysplasia should be confirmed with four-quadrant biopsies taken at $2 \mathrm{~cm}$ intervals for nondysplastic $\mathrm{BE}$ and $1 \mathrm{~cm}$ intervals for suspected dysplastic BE (12). After obtaining a diagnosis of $\mathrm{BE}$ with or without dysplasia, further workup for the presence of dysmotility or hiatal hernia repair should be driven by the presence of symptoms and should be conducted prior to planned endoscopic therapy for dysplastic BE.

Careful consideration of when to perform endoscopic therapy for $\mathrm{BE}$ is critical to achieving desirable outcomes in the prevention of EAC and eradication of dysplasia (11). Patients with nondysplastic BE undergo surveillance endoscopy with biopsies every three to five years (1-3,510,13-17). Patients with dysplastic BE can be challenging in the setting of LGD given the inter-observer variability. Consequently, confirmation by a second pathologist is recommended to establish a diagnosis of LGD (14). BE with LGD has been shown to be successfully eradicated by RFA, specifically (18). Patients with HGD or carcinoma in situ confirmed independently by two pathologists can safely undergo RFA, EMR, or cryotherapy.

There are circumstances which make some endoscopic therapies preferable to others. In situations where the target lesion is circumferential for a long segment $(>3 \mathrm{~cm})$, EMR can result in stricture in as many as $50 \%$ of cases (19). In contrast, nodular mucosal lesions may be more amenable to EMR compared to RFA or cryoablation as these require apposition of ablation or cryotherapy balloons to the entirety of target mucosa (11). While non-dysplastic $\mathrm{BE}$ does not warrant resection in most circumstances, endoscopic eradication should be considered in patients with long segment $\mathrm{BE}$ and those at high risk for developing esophageal cancer, such as patients with a family history of esophageal cancer, those with poorly controlled reflux (12). Patient preparation immediately prior to endoscopic therapy with RFA, EMR, or cryotherapy is identical to that of patients undergoing white-light endoscopy. Our practice is to keep patients nil per os from the night prior to the planned procedure. Diet and medications are reviewed at a pre-operative visit and instructions are communicated in accordance with a plan for general anesthesia.

\section{Procedures}

All endoscopic therapies at our institution are performed in an operating room in the presence of an anesthesiologist and under general anesthesia with endotracheal intubation. Moderate sedation is certainly appropriate for patients without great risk of aspiration. With patients placed in the supine position, an adult endoscope was used to intubate and examine the esophagus. The top of the gastric folds and location of the proximal extent of BE are then delineated along with any other esophageal mucosal findings. After an initial anatomical survey endoscopic therapy is performed.

\section{Endomucosal resection}

\section{Technique}

Following an anatomical survey of the esophagus and stomach, nodules, raised mucosa, and ulcerations are identified. After identification of the target lesion for resection, the endoscope is removed. The EMR apparatus (Duette $^{\mathrm{TM}}$, Cook Medical, Bloomington, Indiana; is assembled ex-vivo and re-introduced with the endoscope into the esophagus (Figure 1A,B). The target lesion is identified and suction is applied. The lesion is suctioned into an end cap on the apparatus and a rubber band is deployed at the base of the lesion. Suction is then released and the lesion can be identified as a pseudopolyp with a rubber band at the stalk (Figure 1C). A sheath is then introduced into the endoscope with a retractable 5 -Fr or $7-\mathrm{Fr}$ snare connected to electrocautery. The sheath is advanced until it is visualized within the endoscopic field and the snare is subsequently deployed. The target pseudopolyp is snared below the level of the rubber band. Once it is visually confirmed that the pseudopolyp is the only structure within the snare, electrocautery is applied with a foot pedal to the snare and the snare is tightened around the lesion. The target pseudopolyp can then be seen completely free of surrounding tissue and at the base of the mucosectomy, submucosal tissue can be identified and inspected for full thickness perforations, underlying $\mathrm{BE}$, or visible vessels that require hemostasis (Figure 1D). The target pseudopolyp can be removed using a suction cap, endoscopic suction, or can be pushed into the stomach where it can be retrieved with an endoscopic net at completion of the procedure. 

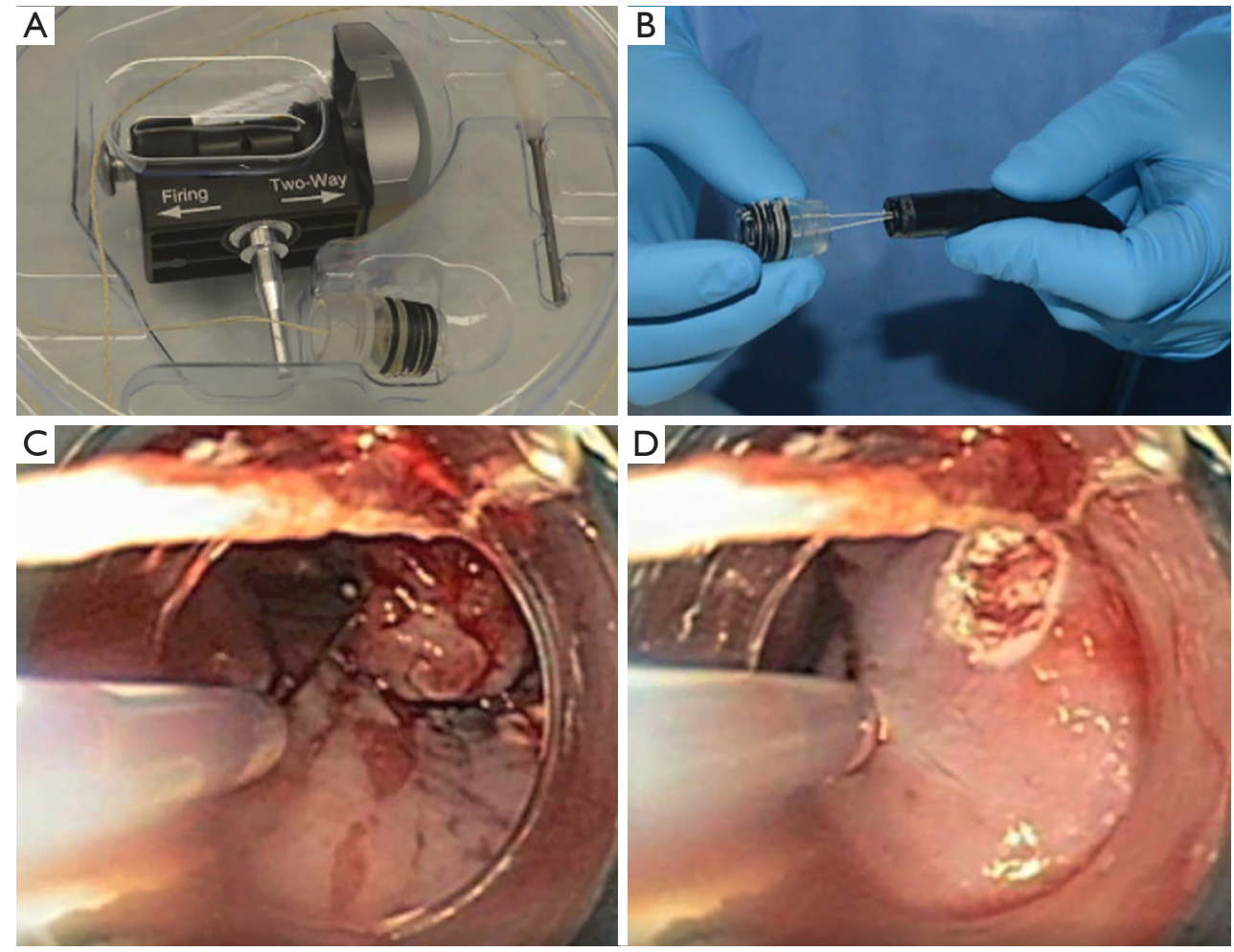

Figure 1 Summary of steps for Endoscopic Mucosal Resection using the DuetteTM, Multi-band Mucosectomy System (Cook Medical, Bloomington, Indiana) (A) Endoscopic Mucosal Resection system; (B) multi-band ligator handle; (C) multi-band system ubber band around pseudopoylp and snare being deployed; (D) post-pseudopolypectomy submucosal surface.

\section{Review of literature}

EMR using multiple techniques has been shown to be a safe method of endoscopic eradication therapy for BE with dysplasia (20-23). Complete eradication of dysplastic BE has been noted in more than $96 \%$ of patients in multiple studies $(20,21)$. Furthermore, EMR has played a role in accurately staging neoplastic BE, with as much as $31 \%$ of patients being re-staged following EMR in one study (22). Multiple large studies have shown that EMR is efficacious in the complete eradication of dysplastic BE more than five years following resection $(20,21)$. Resections are completed in piecemeal in one-third to two-thirds of patients $(20,21)$. Long segment $\mathrm{BE}(>3 \mathrm{~cm})$, piecemeal resection, older age, and advanced pre-treatment histopathology have been identified as independent risk factors for recurrence of dysplastic BE after EMR $(21,24)$.

Complications occur rarely after these procedures, but periprocedural bleeding and perforation requiring further therapy have been noted in fewer than $1 \%$ of patients. Esophageal stenosis is a long-term complication that affects fewer than $5 \%$ of patients and may require further endoscopic intervention in several studies (20-22).

\section{RFA}

\section{Technique}

The esophagus is intubated with an adult endoscope and surveyed for grossly suspicious lesions. Dilute n-acetylcysteine is then used to irrigate the esophagus and a guidewire is passed beyond the gastreoesophageal junction (GEJ) under direct visualization through the side-port of the endoscope. Our preference is to use the BARRX ${ }^{\mathrm{TM}} \mathrm{HALO} 360$ system (MedTronic, Minneapolis, MN) (Figure 2A,B). A sizing balloon is then passed over the guidewire and through the side-port of the endoscope and is inflated under direct visualization proximal to the visualized BE (Figure 2C). The balloon is inflated to the point of circumferential contact with the esophageal mucosa. Ideally, there should be minimal craniocaudal and rotation motion within the esophageal lumen after inflation of the balloon. The sizing 

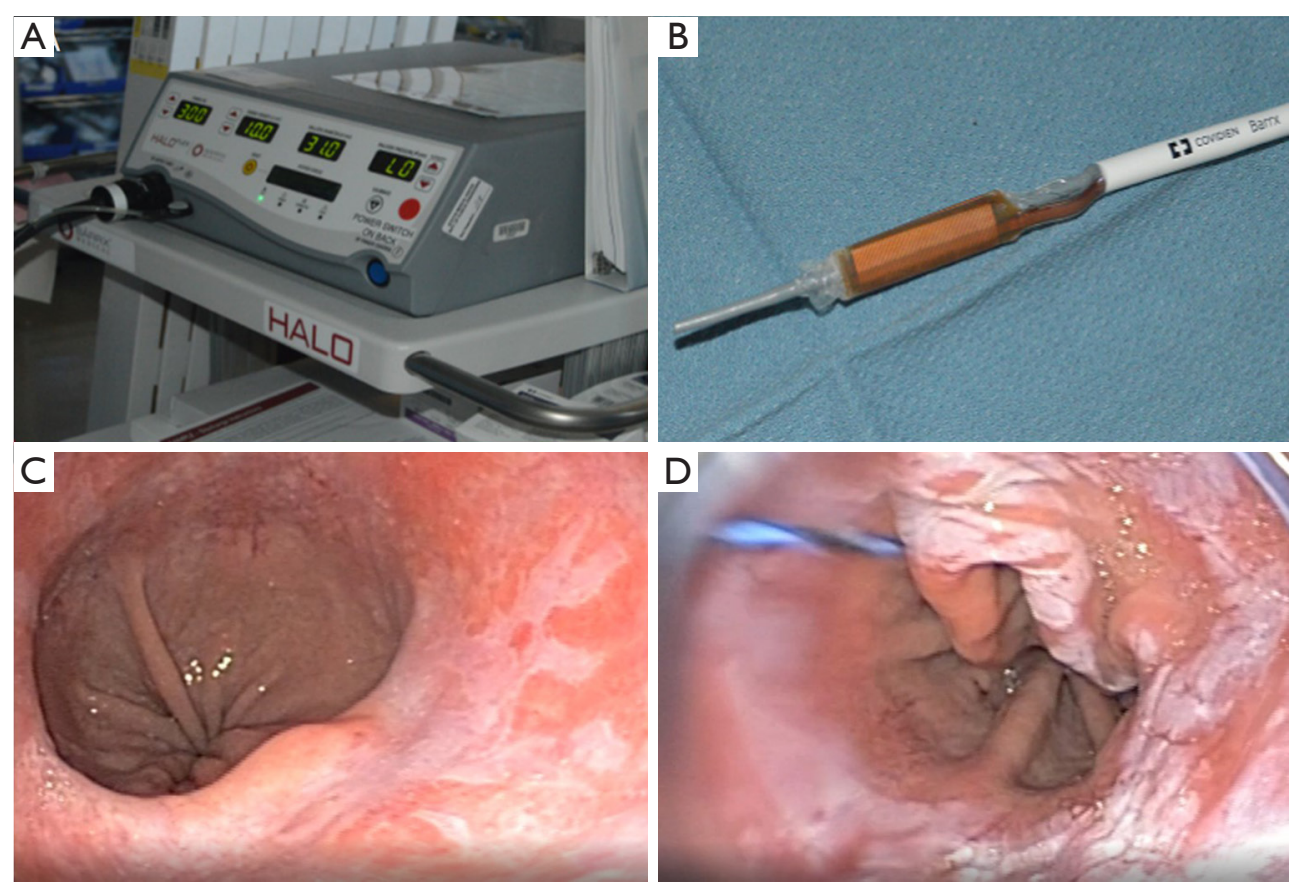

Figure 2 A summary of equipment, targeting, and use of the BARRXTM HALO360 system (MedTronic, Minneapolis, MN) for Radiofrequency Ablation. (A) BARRx system; (B) HALO360 balloon catheter; (C) Targeted BE lesion; (D) post ablation mucosal slough prior to mechanical debridement seen here.

balloon is then removed while keeping the guidewire in place. The ablation balloon is then passed over the guidewire such that the electrode edge is $1 \mathrm{~cm}$ above the proximal extent of $\mathrm{BE}$. The ablation balloon is then inflated and 10 to $12 \mathrm{~J} / \mathrm{cm}^{2}$ of energy is delivered over three seconds. The balloon can be deflated and repositioned as necessary to ablate remaining $\mathrm{BE}$ to the top of the gastric folds. The ablation balloon is then withdrawn, the sloughed mucosa is inspected and mechanically debrided with a friction cap and repeat ablation is performed in the same manner (Figure 2D). Prior to completion of the endoscopy, the esophageal mucosa is examined for full thickness perforations.

\section{Review of literature}

RFA is both safe and effective for the eradication of dysplastic and nondysplastic BE (24-27). Complete eradication of dysplastic $\mathrm{BE}$ has been reported as high as $98.5 \%$ of patients (25). Most studies have shown that over $92 \%$ of patients have complete eradication of dysplasia following RFA with recurrence of dysplastic BE ranging from $4 \%$ to $17 \%$ of patients at follow-up. Several studies have followed patients longitudinally for over three years $(24,26,27)$. Side effects and sequelae of RFA are similar to EMR. There is a low risk of bleeding and perforation in fewer than $1 \%$ of cases that requires further intervention $(18,25)$. More commonly and over a longer period of time, stricture formation requiring dilation can occur in $5-10 \%$ of cases $(18,25)$.

\section{Cryotherapy}

\section{Technique}

The esophagus is intubated with an adult endoscope and surveyed for suspicious mucosal lesions. A nasogastric tube is passed into the stomach parallel to the endoscope and attached to suction to allow for passive and active venting of nitrogen during the procedure. The cryospray system (truFreeze ${ }^{\circledR}$, CSA medical, Lexington, Massachusetts) (Figure 3) is powered on and a full liquid nitrogen tank is confirmed. Following identification of the lesion, a 7-Fr cryospray catheter is advanced through the side channel of the endoscope, again confirming the presence of a decompression tube within the stomach. Once the cryospray catheter is aimed at the target lesion, liquid nitrogen is 
delivered at $-196^{\circ} \mathrm{C}$ until the tissue appears frozen $(20 \mathrm{~s})$ on endoscopic visualization. The tissue is then allowed to thaw and the freeze cycle is repeated two to three times.

Following completion of cryoablation, the cryospray catheter and decompression tube are removed. The esophagus is inspected for full thickness perforations and the stomach is suctioned.

\section{Review of literature}

There are relatively few studies examining the effect of cryoablation in the absence of prior therapies for neoplastic BE (28-30). Cryoablation is safe and has had varying degrees of efficacy among trials, ranging from approximately $80 \%$ complete eradication of dysplastic BE to $100 \%$ (28-30). Recurrence rates range from $14 \%$ to $18 \%$ over follow-up periods up to three years (Thota, gosain) $(28,29)$. While dysphagia requiring dilation can occur in up to $10 \%$ of patients, the most serious adverse event that has been gastric perforation requiring laparotomy secondary to distention in the absence of adequate venting (29-31).

\section{Postoperative care}

Upon completion of endoscopic eradication therapy for $\mathrm{BE}$, patients are recovered in the post anesthesia care unit. Patients in good condition with pain adequately controlled, usually with non-narcotic analgesia such as alternating acetaminophen and ibuprofen, are discharged home. Patients are discharged on twice daily proton pump inhibitors. Patients are initially resumed on a clear liquid diet in the postoperative anesthesia care unit and advanced to a soft diet for two to four days as tolerated. Patients are educated on alarm symptoms such as chest pain, fevers, abdominal pain, dysphagia, inability to tolerate secretions, and dyspnea.

Patients are seen between one and two weeks postoperatively and a follow-up endoscopy is performed one to two months after the index procedure. During this endoscopy the previously treated mucosal lesions should be assessed for the need for either repeat or alternative eradication therapies. The esophagus should be thoroughly inspected for the development of metachronous lesions as well.

\section{Conclusions}

Endoscopic eradication therapy can be performed using
A
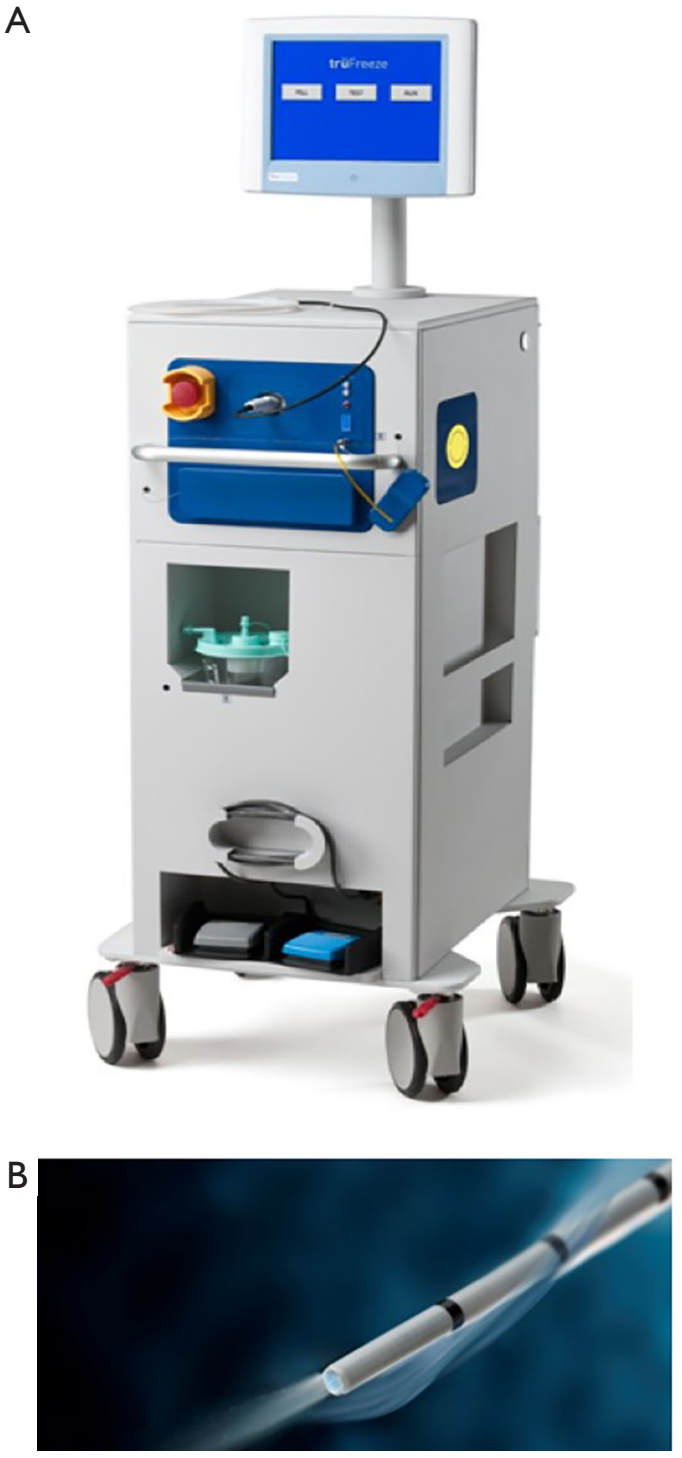

Figure 3 Overview of truFreeze ${ }^{\circledast}$ (CSA medical, Lexington, Massachusetts) cryospray equipment. (A) truFreeze cryospray system and (B) catheter.

a variety of technologies, including EMR, RFA, and cryotherapy. These are all safe and effective technologies which can be used alone or sequence depending on the clinical scenario. Table 1 summarizes findings of recent literature presented in this review regarding the use of EMR, RFA, and cryotherapy. In summary, endoscopic eradication should be considered for patients with dysplastic $\mathrm{BE}$ or intraepithelial neoplasms, or for high-risk patients with non-dysplastic BE. 
Table 1 Review of endoscopic eradication therapy for BE

\begin{tabular}{|c|c|c|c|c|c|c|c|}
\hline Author & Year & Study Type & $\mathrm{N}$ & Method & Follow-up & $\begin{array}{c}\text { Complete } \\
\text { Eradication (\%) }\end{array}$ & $\begin{array}{l}\text { Recurrence at } \\
\text { follow-up (\%) }\end{array}$ \\
\hline Pouw et al. & 2018 & Prospective & 291 & EMR & 30 days $^{A}$ & $97^{\mathrm{B}}$ & - \\
\hline Pech et al. & 2008 & Prospective & 279 & EMR & 63 months & 97 & $23^{\mathrm{C}}$ \\
\hline Larghi et al. & 2007 & Prospective & 26 & EMR & 28 months & 87.5 & - \\
\hline Krajciova et al. & 2019 & Retrospective & 136 & RFA & 28 months & 98.5 & 4.5 \\
\hline Cotton et al. & 2017 & Prospective & 119 & RFA & 40 months $^{\mathrm{D}}$ & 92 & 17 \\
\hline Phoa et al. & 2014 & Prospective & 68 & RFA & 36 months $^{\mathrm{E}}$ & 92.6 & 1.6 \\
\hline Shaheen et al. & 2010 & Prospective & 84 & RFA & 40 months $^{E}$ & $93^{*}$ & 4.2 \\
\hline Thota et al. & 2018 & Prospective & 81 & CRYO & 32 months $^{\mathrm{E}}$ & 78.8 & 14.3 \\
\hline Gosain et al. & 2013 & Retrospective & 32 & CRYO & 37 months $^{\mathrm{E}}$ & 100 & 18 \\
\hline Shaheen et al. & 2010 & Retrospective & 60 & CRYO & 10.5 months $^{\mathrm{E}}$ & 87 & - \\
\hline
\end{tabular}

${ }^{A}$, follow-up interval represents the end-point of the study; ${ }^{B}$, there were 332 lesions, of which $97 \%$ were found to be completely eradicated; ${ }^{\mathrm{C}}$, recurrence in this study was calculated to include metachronous lesions; ${ }^{\mathrm{D}}$, mean follow-up; ${ }^{\mathrm{E}}$, median follow-up. BE, Barrett's Esophagus; EMR, endoscopic mucosal resection; RFA, radiofrequency ablation.

\section{Acknowledgments}

Funding: None.

\section{Footnote}

Provenance and Peer Review: This article was commissioned by the Guest Editor (Ghulam Abbas) for the series "Minimally Invasive Esophageal Surgery", published in Shanghai Chest. This article has undergone external peer review.

Conflicts of Interest: Both authors have completed the ICMJE uniform disclosure form (available at http://dx.doi. org/10.21037/shc.2020.02.08). The series "Minimally Invasive Esophageal Surgery" was commissioned by the editorial office without any funding or sponsorship. The authors have no other conflicts of interest to declare.

Ethical Statement: The authors are accountable for all aspects of the work in ensuring that questions related to the accuracy or integrity of any part of the work are appropriately investigated and resolved.

Open Access Statement: This is an Open Access article distributed in accordance with the Creative Commons Attribution-NonCommercial-NoDerivs 4.0 International License (CC BY-NC-ND 4.0), which permits the non- commercial replication and distribution of the article with the strict proviso that no changes or edits are made and the original work is properly cited (including links to both the formal publication through the relevant DOI and the license). See: https://creativecommons.org/licenses/by-nc-nd/4.0/.

\section{References}

1. Spechler SJ, Souza RF. Barrett's Esophagus. N Engl J Med 2014;371:836-45.

2. Dresner SM, Griffin SM, Wayman J, et al. Human model of duodenogastro-oesophageal reflux in the development of Barrett's metaplasia. Br J Surg 2003;90:1120-8.

3. Hvid-Jensen F, Pederen L, Drewes AM, et al. Incidence of Adenocarcinoma among Patients with Barrett's Esophagus. N Engl J Med 2011;365:1375-83.

4. Portale G, Hagen JA, Peters JH, et al. Modern 5-year survival of resectable esophageal adenocarcinoma: Single institution experience with 263 patients. J Am Coll Surg 2006;202:588-96.

5. Rubenstein JH, Shaheen NJ. Epidemiology, Diagnosis, and Management of Esophageal Adenocarcinoma. Gastroenterology 2015;149:302-17.e1.

6. Sharma P, Falk GW, Weston AP, et al. Dysplasia and cancer in a large multicenter cohort of patients with Barrett's esophagus. Clin Gastroenterol Hepatol 2006;4:566-72.

7. Sikkema M, de Jonge PJ, Steyerberg EW, et al. Risk of 
esophageal adenocarcinoma and mortality in patients with Barrett's esophagus: a systematic review and meta-analysis. Clin Gastroenterol Hepatol 2010;8:235-44; quiz e32.

8. Repaka A, Chak A. Endoscopic management of Barrett esophagus. Nat Rev Gastroenterol Hepatol 2011;8:582-91.

9. Shaheen NJ. Where is the finish line for endoscopic eradication therapy in Barrett's esophagus? Gastrointest Endosc 2019;89:926-8.

10. Shimamura Y, Iwaya Y, Goda K, et al. Endoscopic treatment of Barrett's esophagus: What can we learn from the Western perspective? Dig Endosc 2018;30:182-91.

11. Muñoz-Largacha JA, Litle VR. Endoscopic mucosal ablation and resection of Barrett's esophagus and related diseases. J Vis Surg 2017;3:128.

12. Shaheen NJ, Falk GW, Iyer PG, et al. ACG Clinical Guideline: Diagnosis and Management of Barrett's Esophagus. Am J Gastroenterol 2016;111:30-50.

13. Eluri S, Shaheen NJ. Barrett's esophagus : diagnosis and management. Gastrointest Endosc 2017;85:889-903.

14. Kerkhof M, van Dekken H, Steyerberg EW, et al. Grading of dysplasia in Barrett's oesophagus: substantial interobserver variation between general and gastrointestinal pathologists. Histopathology 2007;50:920-7.

15. Shafa S, Shaheen NJ. Buried Barrett's Esophagus-a Sheep in Sheep's Clothing. J Gastrointest Surg 2016;20:1281-3.

16. Sharma P, Dent J, Armstrong D, et al. The development and validation of an endoscopic grading system for Barrett's esophagus: the Prague C \& M criteria. Gastroenterology 2006;131:1392-9.

17. Souza RF. From Reflux Esophagitis to Esophageal Adenocarcinoma. Dig Dis 2016;34:483-90.

18. Shaheen NJ, Sharma P, Overholt BF, et al. Radiofrequency Ablation in Barrett's Esophagus with Dysplasia. N Engl J Med 2009;360:2277-88.

19. Lewis JJ, Rubenstein JH, Singal AG, et al. Factors associated with esophageal stricture formation after endoscopic mucosal resection for neoplastic Barrett's esophagus. Gastrointest Endosc 2011;74:753-60.

20. Pouw RE, Beyna T, Belghazi K, et al. A prospective multicenter study using a new multiband mucosectomy device for endoscopic resection of early neoplasia in Barrett' s esophagus. Gastrointest Endosc 2018;88:647-54.

21. Pech O, Behrens A, May A, et al. Long-term results and risk factor analysis for recurrence after curative endoscopic therapy in 349 patients with high-grade intraepithelial neoplasia and mucosal adenocarcinoma in Barrett's oesophagus. Gut 2008;57:1200-6.
22. Wani S, Abrams J, Edmundowicz SA, et al. Endoscopic Mucosal Resection Results in Change of Histologic Diagnosis in Barrett's Esophagus Patients with Visible and Flat Neoplasia : A Multicenter Cohort Study. Dig Dis Sci 2013;58:1703-9.

23. Larghi A, Lightdale CJ, Ross AS, et al. Long-term followup of complete Barrett' s eradication endoscopic mucosal resection ( $\mathrm{CBE}$ - EMR ) for the treatment of high grade dysplasia and intramucosal carcinoma. Endoscopy 2007;39:1086-91.

24. Shaheen NJ, Overholt BF, Sampliner RE, et al. Durability of Radiofrequency Ablation in Barrett' s Esophagus With. Gastroenterology 2011;141:460-8.

25. Krajciova J, Janicko M, Falt P, et al. Radiofrequency Ablation in Patients with Barrett's Esophagus- related Neoplasia - Long-Term Outcomes in the Czech National Database. J Gastrointestin Liver Dis 2019;28:149-55.

26. Cotton CC, Wolf WA, Overholt BF, et al. Late Recurrence of Barrett's Esophagus After Complete Ablation in Intestinal Metaplasia Containing Dysplasia Trial. . Gastroenterology 2017;153:681-8.e2.

27. Phoa KN, van Vilsteren FG, Weusten BL, et al. Radiofrequency Ablation vs Endoscopic Surveillance for Patients With Barrett Esophagus and LowGrade Dysplasia A Randomized Clinical Trial. JAMA 2014;311:1209-17.

28. Thota PN, Arora Z, Dumot JA, et al. Cryotherapy and Radiofrequency Ablation for Eradication of Barrett's Esophagus with Dysplasia or Intramucosal Cancer. Dig Dis Sci 2018;63:1311-9.

29. Gosain S, Mercer K, Twaddell WS, et al. Liquid nitrogen spray cryotherapy in Barrett's esophagus with highgrade dysplasia : long-term results. Gastrointest Endosc 2013;78:260-5.

30. Shaheen NJ, Greenwald BD, Peery AF, et al. Safety and efficacy of endoscopic spray cryotherapy for Barrett' $s$ esophagus with high-grade dysplasia. Gastrointest Endosc 2010;71:680-5.

31. Greenwald BD, Dumot JA, Horwhat JD, et al. Safety, tolerability, and efficacy of endoscopic low-pressure liquid nitrogen spray cryotherapy in the esophagus. Dis Esophagus 2010;23:13-9.

doi: $10.21037 /$ shc.2020.02.08

Cite this article as: Sridhar P, Litle VR. Endoscopic eradication therapies for Barrett's esophagus. Shanghai Chest 2021;5:4. 